\title{
CORTÁZAR Y LA REELABORACIÓN DE MITEMAS EN "CUELLO DE GATITO NEGRO"
}

\author{
Cortázar and reworking mythemes in "Throat of a Black Kitten"
}

Diana Ramírez*

\begin{abstract}
RESUMEN
Este trabajo es un acercamiento mitocrítico a un cuento de Julio Cortázar. En "Cuello de gatito negro" hay un cambio en los significados de los símbolos, ya que la feminidad otorga un matiz distinto y confiere un cambio crucial para los símbolos, pues no se trata de la figura del monstruo masculino de la Grecia mitológica, sino una figura que rememora ese instinto primario investido en este, cuyo poder estriba en su dualidad, en su carácter monstruoso.
\end{abstract}

Palabras clave: feminidad, laberinto, Minotauro, mito, Cortázar.

\begin{abstract}
This work is a mitocritical approach to Julio Cortazar's short story, "Throat of a Black Kitten". The purpose of this study is the female character because there is a contrast with other texts in the work of the Argentine author when he uses mythemes like Labyrinth and the Minotaur. "Throat of a Black Kitten" is a change in the meaning of symbols, since femininity gives a different nuance and confers a crucial change for symbols, as it is not the figure of the male monster of ancient Greece, but a figure that recalls the primal instinct invested in this, whose power lies in its duality, its monstrous character.
\end{abstract}

Keywords: femininity, labyrinth, Minotaur, myth, Cortázar.

\footnotetext{
* Universidad Nacional Autónoma de México. Egresada del Doctorado en Letras. México, Correo electrónico: diana.rampe@gmail.com

Recepción: 04-04-16. Aceptación: 10-11-16.
} 
"Sólo hay un medio para matar a los monstruos; aceptarlos".

"Cuello de gatito negro", escrito en 1971, pero publicado en 1974 en la colección de cuentos Final del juego, narra el encuentro casual de Dina y Lucho. Él es un experto seductor de mujeres en el metro, ella una mulata atractiva que coincide con él en uno de los vagones, de tal manera que las manos de ella comienzan un juego que él atribuye a un interés sugerente y Dina se disculpa invitándolo a un café en su casa, lugar donde reitera las justificaciones aduciendo que sus manos tienen vida propia. Lucho, creyendo esto como una forma ingeniosa de disimular, la seduce y, luego de tener sexo, se desencadena una escena en la cual ella le muestra que sus manos son independientes y homicidas.

La trama parece en un principio la representación de un encuentro sexual fortuito; ${ }^{1}$ las imágenes, la estructura y el giro de los acontecimientos desembocan en situaciones inesperadas, lo cual reitera el estilo de Cortázar, tal como señala Graciela De Sola: "Sus cuentos se inclinan a captar - sin violar abiertamente la constitución de la realidad- lo tremendo y lo maravilloso que ella en sí encierra. Sin recurrir a lo insólito, a lo teratológico, a lo 'fuera de serie', Cortázar se enfrenta a lo maravilloso-real, a la irreductible sustancia de que está hecha la vida cotidiana y corriente, a su trasfondo de misterio" (1968, p. 52). Es importante señalar que todo parece cotidiano y familiar, una representación rutinaria, como parte de la lógica interna del texto, narrado de tal forma que la familiaridad de los ambientes y situaciones confrontan la singularidad y la repetición:

Por lo demás no era la primera vez que le pasaba, pero de todos modos siempre había sido Lucho el que llevaba la iniciativa, apoyando la mano como al descuido para rozar la de una rubia o una pelirroja que le caía bien, aprovechando los vaivenes en los virajes del metro y entonces por ahí había respuesta, había gancho, un dedito se quedaba prendido un momento antes de la cara de fastidio o indignación, todo dependía de tantas cosas, a veces salía bien, corría, el resto entraba en el juego como iban entrando las estaciones en las ventanillas del vagón, pero esa tarde pasaba de otra manera. $\left(2000\right.$, p. 106) ${ }^{2}$

\footnotetext{
${ }^{1}$ Cortázar juega con escenarios y contextos que parecen cotidianos para los personajes, pero dan un giro cuando ellos se encuentran dentro de la comodidad de su ambiente. Sobre este rasgo estilístico del escritor argentino, Luis Harss sostiene: "Con el tiempo ha ido descartando los efectos fáciles de la narrativa tradicional; el melodrama, la sensiblería, la causalidad evidente, la construcción sistemática, las amabilidades y las corpulencias estilísticas" (1966, p. 255), es decir, la propia sencillez de la trama adapta al lector a tomar con esa misma noción las situaciones que se le plantean, por lo cual el efecto con el que cierra los cuentos es inesperado y representa la vuelta de tuerca en todos los niveles del relato.

${ }^{2}$ Cortázar, Julio. (2000). Cuentos completos, México: Alfaguara. En adelante, todas las referencias a los cuentos serán citadas sólo por el número de página.

${ }^{3}$ Cortázar, como parte de los mecanismos con los cuales adapta al lector al mundo que le ofrece en sus textos, presenta factores del mundo contemporáneo alternados con la situación distinta a la realidad circundante del lector; dichos factores gradualmente van apareciendo; así, cuando el lector se encuentre ante ellos, no le producirán extrañeza.
} 
Los factores cotidianos, ${ }^{3}$ así como la idea de que la batuta está en manos de un personaje acostumbrado y adaptado a ella, destacan desde el inicio. El espacio (París, y específicamente el metro) revela el primer perfil de un laberinto: la ciudad que, en su enormidad, alberga cualquier tipo de situación o personaje inesperado. También es importante destacar al metro como sitio de uso común, ${ }^{4}$ que permite ver tres tipos de dialécticas: dentro-fuera, público-privado, estática-movimiento. ${ }^{5}$ Además, este vehículo aparece como un laberinto en sí mismo: sitio de encuentros y lejanías, periferia e individualidades, pasillos, encrucijadas.

Cortázar retoma los medios de transporte modernos como parte de los escenarios de sus textos; ${ }^{6}$ el metro se convierte en una de sus atmósferas predilectas para un acontecimiento detonante, que produce un cambio o corte en el sistema de realidad de los personajes y del lector. A su manera, el espacio es un laberinto sin centro alguno, por lo que

\footnotetext{
${ }^{4}$ El metro es uno de los espacios más socorridos en el universo cortazariano; en él sucede que los personajes se desarrollen, busquen y que "además, cada estación puede servir de centro (como lo determinará el juego) de todo el sistema; así el metro parece ser muy adecuado para simbolizar la búsqueda de los protagonistas por un centro, que en realidad no es el centro geométrico de la mandala, sino un punto desde donde todo el sistema tendrá sentido. Y, por fin, las variedades infinitas de posibles viajes en el metro facilitan la representación dramática del azar, elemento indispensable para los juegos" (Scholz, 2009, p. 452).

5 Cortázar trabaja con estructuras o, como él denomina, figuras. Estas, surgen y se articulan de forma tripartita, Cortázar sostenía que esta presencia constante en su obra es intencional, además de que: "Las figuras serían en cierto modo la culminación del tema del doble, en la medida en que se demostraría o se trataría de demostrar una concatenación, una relación entre diferentes elementos que, vista desde un criterio lógico, es inconcebible" (Harss, 1967, p. 292). Las particularidades de este texto implican observar esta noción, ya que en "Cuello de gatito negro" los componentes parecen desarticulados, casuales, pero son formas que articulan la estructura laberíntica.
}

${ }^{6}$ Algunos textos donde el uso de medios de transporte es crucial para el desarrollo de la trama son: Los premios, "Ómnibus", "La autopista del sur", "La isla a mediodía”. El metro es elemental para el desarrollo de otros, como son: "Manuscrito hallado en un bolsillo", "El perseguidor", Rayuela y 62/Modelo para armar, y dado que en ellos se manifiesta la posibilidad de un encuentro con "lo otro", sucede que: "Y por un momento parece que el deseo inscrito en la textualidad cortazariana necesitara de ese extraño -laberíntico- territorio bajo tierra, para manifestarse. Son las nuevas catacumbas de la ciudad moderna, en cuyos circuitos de comunicación el deseo circula de una manera extraña, aviesa. Sólo que ahora el juego no nace del sujeto mismo, más bien el sujeto se ve de pronto inmerso en él, sin saber exactamente de qué se trata, sin poder vislumbrar siquiera sus límites" (Pereira, 2005, p. 231).

${ }^{7}$ Lázló Scholz, en "Un octaedro del Octaedro de Julio Cortázar" diserta sobre este tema de la centralidad, ya trabajado en Rayuela y en otros textos, como parte del ambiente o escenario constante en la obra de Cortázar, sostiene: "los logros resumidos bajo las nociones de circularidad, el lector-cómplice, el auto-enfrentamiento y el azar tampoco conllevan novedades trascendentales en la obra cortazariana. [...] Lo nuevo de este cuento se realiza en el tratamiento de todos estos factores" (2009, p. 458). 
se establece una correspondencia entre la estructura del relato y los espacios del cuento, negado a centralizar sus contenidos. ${ }^{7}$

Mediante el espacio se reitera la idea de descenso, pues todo comienza en un mundo subterráneo, el cual simboliza la profundidad de la naturaleza de los personajes, quienes se mueven instintivamente. De esta forma, ellos y el espacio van construyendo la estructura del cuento con parámetros que crean un laberinto, ya que los instintos encubren una red de situaciones para evocar una serie de actos continuos, como lo es dar vueltas en el laberinto: pasar constantemente por el mismo punto y hallarse perdido. ${ }^{8}$

"Cuello de gatito negro" es un relato determinado por la naturaleza de los personajes. Jaime Alazraki al hablar de este tipo de relatos cortazarianos, señala: "En el 'cuento de argumento' lo central es una situación y los personajes contribuyen a precipitarla; en el 'cuento de personaje' el foco de la narración es un personaje o personajes, y el argumento y demás ingredientes del texto suministran las circunstancias que hacen posible su desarrollo" (1983, p. 131). En "Cuello de gatito negro" el foco de la narración son Dina y sus manos; a partir de ellas, la estructura del texto se construye en espacios y significados, todo se articula en torno al conflicto del personaje. Desde esta propuesta de lectura, Dina aparece como una variante del Minotauro; solo que a diferencia del monstruo cretense, la mixtura de su condición oscila entre ser una fémina "normal" y la siniestra realidad de sus manos en la oscuridad. Dina evoca la naturaleza heterogénea que se desea mantener oculta; es el monstruo contenido en un espacio determinado, cuya condición la aísla y la vuelve única. En este sentido, reiterando la constante y emblemática presencia de esta figura mitológica, es posible agregar:

This confrontation of the monster and the hero constitutes the primal scene in Cortázar's mythology of writing: a hegemonic struggle for the center that resolves itself in a mutual cancellation and in the superimposition of beginnings and ends. The very image of a man unborn, the Minotaur is the possessor of the immediate but naïve knowledge of man before the Fall. His speech is in the incoherent, symbolic language of a savage god. (Alazraki, 1976, p. 66)

Gracias a ella, personaje clave para la estructura, se desarrolla un recurso aparecido en la narrativa de Cortázar: se amplía un aspecto de la realidad y se descontextualiza hiperbolizando sus rasgos, de modo que se evidencian características ocultas por la cotidianidad (en este caso, los movimientos involuntarios de las manos). En este sentido, es posible ver en Dina lo oscuro o nocturno de la feminidad, pues ella representa esta dualidad jugando con la idea de luz-oscuridad que sucede en la habitación, así como con su

\footnotetext{
8 "La combinación de ambas perspectivas (el espacio y la dialéctica del adentro-afuera) hace reflexionar al lector sobre la alegoría de tal construcción como el universo: ¿vivimos en un laberinto sin darnos cuenta?"(García Pérez, 2008, p. 219).
} 
comportamiento tímido en lo público, seductor en la intimidad. Si bien Dina aparece descrita de modo que no encaja en los gustos comunes de Lucho, a través del espacio donde habita es posible adentrarse en el personaje:

La pieza era bastante grande y muy caliente, con una azalea y una lámpara de pie y discos de Nina Simone y una cama revuelta que la chica avergonzadamente y disculpándose rehizo a tirones. Lucho la ayudó a poner tazas y cucharas en la mesa cerca de la ventana, hicieron un nescafé fuerte y azucarado, ella se llamaba Dina y él Lucho. Contenta, como aliviada, Dina hablaba de la Martinica, de Nina Simone, por momentos daba una impresión de apenas núbil dentro de ese vestido liso color lacre, la minifalda le quedaba bien, trabajaba en una notaría. (p. 110)

La descripción del personaje, ${ }^{9}$ si nos aventuramos a determinar también por el espacio, viene a crear una relación más profunda con el mitema del laberinto, llevándolo más allá de un mero elemento contextualizador. En este lugar Dina se vuelve otra cosa, ${ }^{10}$ algo más que escapa a las tentativas de un personaje seductor o meramente esquizoide. ${ }^{11}$

Dina es la representación, por una parte, de lo femenino que devora, pero, por otra, es también una figura que posee el sello del Minotauro, presencia recurrente en la prosa de Cortázar, monstruo cuya presencia termina generando consecuencias trágicas: "A creature half bull and half man is the image of man driven by his lower instincts, imprisioned in the materiality of his senses, unable to exercise his spiritual and intellectual powers" (Alazraki, 1976, p. 65).

El carácter temático de "Cuello de gatito negro", entonces, va mucho más allá de un encuentro sexual o de una historia donde lo casual termina consumiendo a los protagonistas. Desde la presente lectura, partiendo a su vez del texto y continuando con la

\footnotetext{
${ }^{9}$ Una coincidencia importante, que establece un nexo entre Dina y otros personajes de los cuentos de Cortázar, es su condición de extranjera (procede de Martinica). Esta situación los coloca también fuera de una realidad social y cultural, ya que en su mayoría, como Horacio Oliveira, son inmigrantes americanos en Francia, infiltrados en otra realidad, otra lengua, otro sistema de sociedad. Son otros dentro de la otredad.

${ }^{10}$ El doble es un elemento fundamental en los textos de Cortázar; sobre este tema es posible retomar la siguiente aportación: "La duplicidad como característica general de la obra cortazariana evidentemente surgió antes de que apareciera Rayuela. Ya en 'Lejana' vimos un mundo doble (Buenos Aires y Budapest) a través de los ojos de la protagonista, pero fue en esa novela donde la división binaria tanto del mundo objetivo como del subjetivo llegó a ser dominante en todos los niveles de la obra. En cuanto al espacio representado de tal manera, basta acordarnos de las ciudades de París y Buenos Aires, las cuales dialécticamente se complementan en toda la novela, deslizándose una a la otra porque no pueden representar el mundo sino juntas. El dibujo de la rayuela misma, este mundo reducido, tiene también dos polos: el Cielo y la Tierra" (Scholz, 2009, p. 448).

${ }^{11}$ Si bien el carácter de Dina posee rasgos esquizoides, no es interés de este análisis profundizar en tal cuestión. Sobre su lado erótico, la figura del gato y el aspecto de la esquizofrenia existe un trabajo titulado "La figura del gato en la cuentística de Julio Cortázar", de Humberto Payán Fierro, aparecido en Syntesis (2009).
} 
línea de investigación que fundamenta la presencia del Minotauro en la obra del autor argentino, en este texto la presencia de lo mítico se abre paso a través de la construcción de las estructuras espaciales, del interior de los personajes y del contenido simbólico investido en la figura del Minotauro.

La escritura de Cortázar muestra cómo en la reelaboración literaria los personajes están condenados a la fragmentación por su falta de osadía para encarar la realidad que ellos mismos contienen. La idea del monstruo como un ser perteneciente a una realidad distinta pervive en algunos relatos de Cortázar ("Después del almuerzo" (1956), "Las armas secretas" (1959), "El otro cielo" (1966), "En nombre de Boby” (1977)), así como el mitema del laberinto (Rayuela (1963), 62/Modelo para armar (1968). ${ }^{12} \mathrm{Si}$ bien el propósito de resemantizar el mitema del monstruo único encerrado en un laberinto es propio de Los reyes (1949), la situación de Dina es variable, puesto que el laberinto donde se mueve es París; su núcleo es la pieza pequeña donde reside y dentro de la cual sucede la mayor parte del texto (ella no es un monstruo, es alguien que vive con el hecho monstruoso de tener manos independientes de su voluntad, quienes parecen obligarla a pertenecer a una siniestra realidad).

La constante aparición del Minotauro y del laberinto posee implicaciones para reiterar los tópicos del encierro, del monstruo; estas revelan al hombre escindido y fragmentado, incapaz de crear, perdido en la realidad otra que él mismo contiene; porque el monstruo en la obra de Cortázar no representa lo horrible ni lo grotesco: ${ }^{13}$ por el contrario, más allá de la estética, de lo femenino y de lo masculino como elementos exclusivos de uno $\mathrm{u}$ otro sexo, el conflicto es la incapacidad para afrontar una determinada condición dual, así como la negación a la tentativa de romper los hábitos que estipulan la existencia. En el interior del mundo cotidiano de Cortázar, dentro del cual participan los detalles inesperados

\footnotetext{
${ }^{12}$ A este respecto cabe agregar que: "Lo bestial es al mismo tiempo algo que el hombre custodia y contra lo cual combate, y también algo que lo constituye y lo explica. [...] [Los personajes] sienten esa ambigüedad que ya conocían los antiguos cuando afirmaban que los monstruos excitaban en ellos a la vez el terror y el deseo" (García Canclini, 1968, p. 28), porque precisamente lo bestial expresa la doble realidad que habita el hombre, negada, oculta. El Minotauro es un ejemplo ilustrativo por su carácter de monstruo mixto, cuyos componentes muestran en su imagen una inversión de la naturaleza (la cabeza de toro) cuando debiera representar lo racional y, el cuerpo de hombre, que debería ser la representación del instinto animal.

${ }^{13}$ En los textos de Cortázar, desde sus inicios como escritor, además del tema del monstruo y del laberinto aparece como constante el terror por las pasiones y por lo que ellas detonan, entendidas estas como una manifestación de la realidad humana; Graciela De Sola comenta en este sentido acerca de Bestiario: "La naturaleza aparece como monstruosa y terrible; ella es la autora del proceso que desencadena cambios angustiosos en los vagos protagonistas del relato. La objetivación de la angustia, del horror por la realidad manifiesto en todo el libro" (De Sola, 1968, p. 47).
} 
o cuyo papel es más crucial de lo aparente, García Canclini ha propuesto: "otra constante de Cortázar: la profanación de lo falsamente sacralizado o de aquello que con su fama oscurece las formas menores o nos 'exime' de profundizar en lo cotidiano; esa profanación busca exaltar el valor silenciado de lo menor, de lo marginal, tanto en el arte como en la vida" (1968, p. 89). Cortázar reelabora la figura del Minotauro, quien dentro de la obra del narrador argentino tiene un papel cuya función cambia la del mito original:

El Minotauro simboliza, además, lo monstruoso que se nos opone, la frontera del poder y el conocimiento del hombre. Matarlo equivale a conocerlo. Pero ese saber, irreverente con el secreto de laberinto, acaba empobreciéndonos. No podemos aprehenderlo todo, porque la realidad no es totalmente reductible al conocimiento ni comprensible por la razón. Cuando la violentamos para que quepa en categorías racionales, destruimos los monstruos, y sin ellos quedamos solos, tristes. (1968, p. 20-21)

La aniquilación del monstruo anula, destruye las posibilidades de cambio. "El hombre nuevo, el gran reconciliado", esa figura que Cortázar perfila en su obra como una aspiración humanística, precisamente emprende y persigue la cohesión de sus fracciones internas; la creación del ser está basada en la conciliación de los opuestos. Cortázar afirma en Los reyes que "sólo hay un medio para matar a los monstruos; aceptarlos" (1970, p. 30). Cortázar parte de la literatura como creación, entendiendo dentro de ella la mixtura de la naturaleza humana, concebida igual que su narrativa, como una "mezcla de heterogeneidades" (Cortázar/1, 1994, p. 81) y en su visión poética del hombre se consolidan en la aceptación del monstruo como una parte crucial para asumir la estructura de lo poético en sí mismo:

La visión poética está íntimamente arraigada en su espíritu. Ella condiciona en forma constante un sentido rescatador de esencialidad, restablecedor de nexos, unificador de lo dispar. Tal ambición se expresa en formas analógicas como la metáfora (analogía verbal) o, más frecuentemente, a través de figuras que apuntan a un plano mítico (analogía formal), ambas igualmente referidas al plano ontológico. (De Sola, 1968, p. 149)

Entonces, mediante tal construcción, el texto muestra que: "Lo poético no alude al género literario sino al modo de experimentar la realidad y de recrear el lenguaje" (García Canclini, 1968, p. 19-20). No hay una sola versión ni una sola naturaleza en el planteamiento literario; este está interpretando al hombre de su tiempo y, simultáneamente, al hombre como ser humano en un eterno retorno a sus costumbres, hábitos y repeticiones. Como se ha visto, Cortázar perseguía un replanteamiento de las estructuras que construyen al hombre, que lo crean. Si le parecía necesario replantear y reelaborar la concepción de mito, esto sucede porque son situaciones inherentes a su obra, precisamente por la postura que el escritor mantiene, tal como señala García Canclini al relacionar lo poético como forma de mirar la realidad: 
Es que lo poético no está dado en él por la forma exterior del lenguaje, sino por el carácter de la intuición y las imágenes que la revelan. Por lo mismo, no encontraremos una idea del hombre expresada poéticamente; ambos elementos viven enlazados en una síntesis inseparable. Más allá de caducas distinciones entre contenido y forma, su obra se erige como una experiencia poética de lo humano. (1968, p. 19)

El monstruo, entonces, es la alegoría de una serie de deseos representantes de lo negado e ineludible. La fuerza de las manos del personaje la mantiene encerrada en el laberinto, y ello revela a este mitema como lugar común a los seres humanos, como la alegoría de inquietudes y cruce de caminos por los que atraviesa el ser. Cortázar, mediante el diálogo de Ariadna en Los reyes, expresa esta condición: "Nadie sabe qué mundo multiforme o qué multiplicada muerte llenan el laberinto. Tú tienes el tuyo, poblado de desoladas agonías [...] Mi laberinto es claro y desolado, con un sol frío y jardines centrales donde pájaros sin voz sobrevuelan" (Cortázar, 1970, p. 8). ${ }^{14}$

Dina también expresa su soledad, la incomprensión, el aislamiento, su falta de credibilidad y la cruda traición de su cuerpo a su mente. Todas las acciones ocurren en la oscuridad de la habitación, donde el sexo sucede porque ella no mira sus manos, todo deja de importar para abandonarse al placer, dentro del cual, curiosamente, coinciden ambos planos de la realidad cuerpo-mente. Pero el goce no dura mucho, pues ella no puede olvidar de forma permanente su condición:

En algún momento las preguntas volverían, las ahuyentadas que la oscuridad guardaba en los rincones o debajo de la cama, [...] le dijo que vivía sola, que nadie le duraba, que era inútil, que había que encender una luz, que del trabajo a su casa, que nunca la habían querido, que había esa enfermedad, todo como si no importara en el fondo o fuese demasiado importante para que las palabras sirvieran de algo, o quizá como si todo aquello no fuera a durar más allá de la noche y pudiera prescindir de explicaciones, algo apenas empezado en una barra de metro, algo en que sobre todo había que encender una luz. (p. 113)

En esta descripción destacan los elementos para exaltar a los amantes como sujetos unidos momentáneamente dentro del laberinto. Dina y Lucho aparecen enlazados en el instante poscoital donde se pretende acceder a un conocimiento profundo del otro, como si el sexo motivara a profundizar más allá de la carne, inquiriera ahondar en los diálogos afirmándose en una permanencia breve, pero a la que no es posible aferrarse. ${ }^{15}$ Este tiempo

\footnotetext{
${ }^{14}$ Como ya se ha mencionado, en esta obra aparece lo que en la perspectiva de algunos críticos se convertirá en una de las escenas primordiales en la obra de Cortázar: "This primal scene appears with remarkable consistency in Cortázar's writing. I do not mean simply than there are monsters, labyrinths and heroes, but rather that the scene in which a monster and a hero kill each other, cancel each other's claim for the center of the labyrinth, occurs with grand frequency" (Alazraki y Ivask, 1976, p. 67).
} 
se fractura con la imperiosa necesidad de Dina por la luz, para que termine su angustia y vuelva a la seguridad de vigilar sus manos que la inquietan, la acosan y, por supuesto, son la expresión de todo lo negado:

La búsqueda de la luz física es el intento por subsanar la carencia de una condición sin la cual no hay posible redención: el control sobre el cuerpo. [...] El cuerpo es por tanto seudo-componente del ser o, más propiamente, su estación de paso, ya que, a diferencia del alma, está sujeto a los poderes corrosivos del tiempo y condenado a su más temible consecuencia, la muerte. (Chico Quintana, 2008, p. 6364)

La perspectiva anterior propone una escisión espiritual, demarcada por los factores duales luz-oscuridad. Su instinto se superpone a su razón y ella desearía ocultar el instinto. Esto propicia que Dina conciba su conducta como un tipo de monstruosidad que ella no comprende, creada por la separación entre el cuerpo y la idea que el personaje posee de cómo ser socialmente aceptable. Las manos de Dina son el emblema de la ruptura con lo corporal, muestran cómo algo tan usual y cotidiano no corresponde a la realidad deseada. Cortázar revela que la realidad corpórea también puede ser habitante de otra realidad, solo que en este caso el doble no es otro personaje, sino que está contenido dentro de ella. ${ }^{16}$

\footnotetext{
${ }^{15}$ Este tipo de imágenes en la poética de Cortázar aparecen tanto en un sentido asociado con la carga erótica evidente así como a la propuesta poética que menciona García Canclini. Este aspecto de la unión no solo se revela como dualidad, sino como posibilidad de encuentro, así como de juego: "Finalmente, el juego es el momento de la incertidumbre, la oportunidad tanto de perder como de ganar; parte de la seducción que ofrece al adulto radica en el vértigo del resultado, en que introduce el riesgo en esa seguridad inmóvil de la madurez, deseada cuando no se la tiene, monótona cuando llega; incertidumbre que de algún modo es el símbolo de otra, la del camino a la tragedia o a la dicha" $(1968$, p. 64).

${ }^{16}$ Una vez más aparece la imagen del monstruo que habita el instinto: "La "monstruosa discrepancia", "la doble condición animal" de la que habla el Minotauro es ser corpóreo, ser momentáneo, ser inmanente, ser sexual. Entre la autodefinición y la anulación hay una derrota compartida, allí habita la invulnerabilidad del laberinto: Dina no puede renunciar al doble fracaso, no saberse el monstruo es igual a no serlo" (Chico Quintana, 2008, p. 72). De allí la violenta reyerta del personaje pues, por una parte, la lucha interior se manifiesta en la agresión a Lucho y, por otro lado, en el castigo de no permanecer acompañada.

${ }^{17}$ Precisamente este doble se apacigua durante la cópula, cuando los instintos rompen momentáneamente la individualidad mediante el placer. Destaca también que en este punto de la narración la intimidad se hace aún más profunda por el hecho de suceder en el hogar de Dina, un espacio determinante del cuento. El placer, como uno de los juegos de Cortázar, permite ser auténticamente. Asimismo, este tema se convierte en una polémica para la crítica, pues también: "Los personajes cortazarianos sufren de atrofia crónica para el amor recuérdese al mayor de los paralíticos, Horacio Oliveira. La expulsión del otro (Lucho) obedece a un principio narratológico cortazariano: las formas del amor son siempre una invasión amenazante [...] y ante ella se debe reaccionar" (Chico Quintana, 2008, p. 69).
} 
La respuesta ante la invasión es la huida o la persecución. ${ }^{17}$ Una vez más aparece el ciclo de retornar al mismo punto; tal situación expresa una constante, otra forma de observar los vínculos emocionales en el mundo literario de Cortázar. Las reproducciones de conducta, de hechos, presentados desde el inicio del relato como una eterna recreación revelan una estructura cíclica, la cual exterioriza ligeras variables: "Por lo demás no era la primera vez que le pasaba, pero de todos modos siempre había sido Lucho el que llevaba la iniciativa" (Cortázar, 1994, p. 106), y son precisamente los hechos diversos los que desencadenan la diferencia, la ruptura del ciclo, lo cual se vuelve revelador al momento de concebir que ya no es un doble, sino una repetición que, si bien duplica las conductas, también es un elemento externo que provoca un cambio; en este caso, las manos de Dina, a quien se ha observado como: "Dina es una representación del maniqueo espíritu occidental, [...] mientras que a la sombra se entrega al éxtasis de una filosofía corporal, sólo para que a la luz del día le encaje bien en la espalda la autoflagelación, sintiéndose lo suficientemente sucia" (Chico Quintana, 2008, p. 73).

El final del cuento presenta el aspecto solitario, brutal, y anuncia que no es un término, solo la desaparición de ciertas circunstancias y, por ende, el reinicio del ciclo: "que echen la puerta abajo, que te limpien la cara, que te cuiden y te protejan porque yo ya no estaré ahí, nos separarán enseguida, verás, nos bajarán separados y nos llevarán lejos uno de otro, qué mano buscarás, Dina, qué cara arañarás" (2000, p. 116). Si el texto presenta el mitema del Minotauro reinsertado en el ambiente contemporáneo, otra de las distancias con el mito original es que el monstruo no es asesinado: no hay heroísmo, sino un desencuentro en el que el significado original, donde esta figura mixta acecha en la oscuridad, persiste. Este ambiente de soledad continúa, no importan género ni contexto, el aislamiento y el dolor asoman en la personalidad de Dina. Lucho resulta incapacitado para redimir al monstruo: no hay héroes ni villanos, solo instintos y soledad.

La tendencia del mitema motiva a pensar en el hombre recontextualizado mediante la literatura, quien no cambia ni instinto ni represiones sociales. En el mundo cotidiano existe una separación de lo que se muestra en las zonas iluminadas y públicas, pero precisamente ese mundo cotidiano, con sus iluminaciones, es lo que conduce al laberinto, cuya entrada es inesperada y, por ende, no hay un centro: ${ }^{18}$ no existe un punto específico,

${ }^{18}$ Sobre la centralización, tema que ya se ha tocado antes en este texto, es posible complementar esta idea de la siguiente forma: "se dice en Rayuela, contra lo absurdo de los ejes, centros, geometrías, 'nombres de la nostalgia indoeuropea'. Así tenemos una razón más para señalar que el doble plano - sin duda alguna- no puede ser un fin estético para Cortázar, sino que es un mero elemento estructural, es algo artificialmente abstraído; lo consideramos como una instantánea radiográfica que captó nada más que un segundo de la realidad en movimiento, en cambio permanente. 'No hay centro-dice Oliveira, -hay una especie de confluencia continua, de ondulación de la materia'" (Scholz, 2009, p. 451).

${ }^{19}$ Sobre este tema, García Canclini ha señalado lo siguiente: "Lo insólito, lo increíble, es a menudo el verdadero rostro de la realidad. Parece excepcional porque lo disimulamos para evitar su 
sino que lo oscuro acecha en lo cotidiano; muestra así que es parte del ser, no es algo señalado o evidenciado, sino manifiesto al abrirse paso en sitios inesperados porque la claridad es engañosa. ${ }^{19}$ En este sentido, los personajes requieren un doble como justificante: "que busquen al doble que sea capaz de superar los obstáculos inmensos en encontrar al otro, porque no hay otro remedio para aguantar la realidad que sustituirla con una llamada irrealidad que es la futura realidad" (Scholz, 2009, p. 454). Las dos realidades se rigen por los instintos, pues si bien los dos personajes conocen su condición, la transgresión a sus hábitos se da con el encuentro entre ambos:

La dimensión arquetípica del laberinto dentro del contexto del presente trabajo entronca con algo más amplio. Del mismo modo que el laberinto de Los reyes aprisiona a sus protagonistas en disyunción trágica ("la doble hacha"), considero que encierra a los personajes de "Cuello de gatito negro" de un modo que compromete su condición de modelos humanos y no su adscripción socio-histórica. Como expresión sí de una herencia cultural más amplia, la ontología occidental. (Chico Quintana, 2008, p. 62)

Entonces, acorde con el argumento anterior, Cortázar se vale de los personajes para estructurar una nueva dimensión: juega con sus papeles, con el inicio de la historia narrada $\mathrm{y}$, reelabora las constantes míticas de tal forma que la realidad presentada para el lector ha cambiado y, además, no se mantiene estática, el juego con los giros y lo inesperado acomete a cada momento. El papel de lo lúdico es fundamental: "Al juego le atribuye Cortázar muchas funciones, pero la más importante es la de ir más allá de lo cotidiano, descubrir 'todo lo que está al otro lado de la Gran Costumbre', abrir una puerta hacia lo desconocido. Ese otro lado puede significar una gran cantidad de cosas, de trascendencias, logros existenciales, amor, etc.” (Scholz, 2009, p. 454).

La cacería sexual se convierte en sobrevivencia. Efectivamente, en este cuento el autor obliga al lector a ir más allá de lo cotidiano, a adentrarse en la profundidad de emociones y contradicciones que no se desean en una situación de placer casual, pero dentro de la cual el gozo se ha saboteado y en su lugar sencillamente se encuentran de cara con el lado vedado de su naturaleza. En este sentido es posible coincidir en la siguiente afirmación de la crítica: "Cortázar no garantiza éxitos; lo que exige es que todos traten de liberarse del sentimiento de descolocación ('de no estar del todo en cualquiera de las estructuras, de las telas que arma la vida y en las que somos a la vez araña y mosca'), y que a través del juego se esfuercen por alcanzar el encuentro anhelado" (Scholz, 2009, p. 457).

incomodidad. Al mezclar imperceptiblemente lo fantástico y lo real, Cortázar revela con qué astucias montamos sobre lo más auténtico las máscaras que conviene exhibir” (1968, p. 32). 
Entre Dina y Lucho los papeles al final del juego se han invertido por completo: el cazador ha caído en la trampa y su vulnerabilidad se expresa en la desnudez de su cuerpo; Dina arremete contra ella misma para saciar los impulsos de sus manos; el acto de encontrarse sexualmente, que debiera ser privado, termina siendo una exhibición para los vecinos, dotando de vulgaridad la escena, restándole cualquier indicio de encuentro sublime ${ }^{20}$ :

Empezó a golpear la puerta mientras escuchaba las voces en el departamento de enfrente, la carrera de la vieja que bajaba llamando a madame Roger, el inmueble que se despertaba en los pisos de abajo, preguntas y rumores, un momento de espera, desnudo y lleno de sangre, un loco furioso, madame Roger, abríme Dina, abríme, no importa que siempre haya sido así pero abríme, éramos otra cosa, Dina, hubiéramos podido encontrar juntos, por qué estás ahí en el suelo, qué te hice yo, por qué te golpeaste contra la puerta, madame Roger, si me abrieras encontraríamos la salida, ya viste antes, ya viste cómo todo iba tan bien, simplemente encender la luz y seguir buscando los dos. (p. 116)

El encuentro deseado, que en este caso es la aceptación, o por lo menos el hecho de que lo monstruoso en Dina por un momento se detenga, no sucede. Los deseos de ambos se ven defraudados, porque si bien Lucho obtiene el placer sexual, aún desea continuar la relación, pero ello no es posible, tal como lo demuestra la lejanía de una puerta cerrada en su rostro, ante su desnudez. El anhelo de amor manifestado por él expresa un ejemplo de lo que expone De Sola: "A la manera neoplatónica, Cortázar parece concebir al amor como un puente o camino hacia la realidad última, hacia lo uno. Sin embargo, asoma una actitud desesperanzada, una constatación de la soledad en el amor" (1968, p. 123).

La búsqueda no da resultados y tampoco tiene un final feliz. Sin embargo, la narración también genera un efecto estético en este conjunto de contrastes, pues Cortázar muestra que, aún en la destrucción, la imagen poética se sostiene: "Así descubrimos que la belleza puede manar de los contrastes, que la reunión de los extremos instaura nuevas armonías. [...] El lenguaje de Cortázar intenta la belleza alejándose de lo que convencionalmente se considera bello" (García Canclini, 1968, p. 88). Entonces, la presencia de lo mítico, tal como sostiene De Sola:

Es explicable, por tanto, la soltura con que Cortázar accede al territorio de los mitos clásicos. Vuelve a vivirlos, ajeno a toda incorporación "libresca", desde su raíz. Su mirada de contemplador abarca la totalidad de lo real, supera la circunstancia fenoménica de tiempo y espacio y aprehende gestos y rostros arquetípicos. [...] lo mítico no aparece ya con la misma evidencia formal, pero sí incorporado a la sustancia profunda de toda la labor de Cortázar. (1968, p. 150)

\footnotetext{
${ }^{20}$ Esta situación de exhibir una escena íntima aparece también en "El río" (1964). El propósito parece vulgarizar lo privado poniéndolo delante del morbo de una multitud o, como en el presente cuento, de unos cuantos mirones.
} 
En el proceso de la literatura, el mito transita mediante una acepción que parece fantástica para el lector en una primera aproximación, pero resulta cotidiana para los personajes, es decir, posee un sentido, de tal manera que el extrañamiento por tal situación se convierte en la lógica dentro de la cual se estructura el universo narrativo. El lector ya no lo cuestiona o mide con la lógica de su mundo, porque la literatura lo ha convertido en un elemento concreto que cohesiona los dos mundos. Como si a través de ella pudiera al menos crearse una estructura que concediera sentido a emociones y conflictos humanos que atañen tanto al creador, al lector y a los personajes.

\section{Referencias}

Alazraki, Jaime. (1983). En busca del unicornio: los cuentos de Julio Cortázar: elementos para una poética de lo neofantástico. Madrid: Gredos.

Alazraki, Jaime and Ivar Ivask. (1976). The final island: The fiction of Julio Cortázar. University of Oklahoma Press: Norman.

Chevalier, J. y Gheerbrant, A. (1986). Diccionario de los símbolos (Trad. Manuel Silvar y Arturo Rodríguez). Madrid: Herder.

Chico Quintana, Rafael. (2008). "La promesa del Minotauro", Visitas al patio. 1 (1). Disponible en: http://www.academia.edu/8200709/La_promesa_del_minotauro Consulta: 15 de diciembre de 2013.

Cortázar, Julio. (1970). Los reyes. Barcelona: Ediciones B.

Cortázar, Julio. (1994). Obra crítica/l. Edición de Saúl Yurkievich. México: Alfaguara.

Cortázar, Julio. (1994). Obra crítica/2. Edición de Jaime Alazraki. Buenos Aires: Alfaguara.

Cortázar, Julio. (2000). Cuentos completos, Tomos I y II. México: Alfaguara.

Cortázar, Julio. (2000). Rayuela. Madrid. Cátedra.

Cortázar, Julio. (2004). Obra crítica, Tomos 1, 2, 3. Edición de Saúl Sosnowski. Buenos Aires: Punto de Lectura.

De Sola, Graciela (Graciela Maturo). (1968). Un puente para el hombre nuevo. Buenos Aires: Sudamericana.

García Canclini, Néstor. (1968). Cortázar. Una antropología poética. Buenos Aires: Nova.

García Pérez, David. (2008). "Reverberaciones grecolatinas del mito del Minotauro en Jorge Luis Borges y Julio Cortázar". Noua Tellus. Anuario del Centro de Estudios Clásicos. Universidad Nacional Autónoma de México, Instituto de Investigaciones Filológicas.

Harss, Luis. (1966). “Julio Cortázar, o la cachetada metafísica”, Los nuestros. Buenos Aires: Sudamericana.

Payán Fierro, Humberto. (2012). "La figura del gato en la cuentística de Julio Cortázar". Synthesis. Facultad de Filosofía y Letras/Universidad Autónoma de Chihuahua. Disponible en: http://www.uach.mx/extension_y_difusion/synthesis/2009/08/20/La_figura_del_gato_en_la_cuentistic a_de_julio_cortazar.pdf Consulta: 11 de diciembre de 2012. 
RAMÍREZ: Cortázar y la reelaboración de mitemas...

Pereira, Armando. (2005). Deseo y escritura: la narrativa de Julio Cortázar. México, D.F.: Universidad Nacional Autónoma de México.

Scholz, László. (2009). “Un octaedro del Octaedro de Julio Cortázar”. Revista Iberoamericana, 42 (96-97), 447-458. Disponible en: http://revistaiberoamericana.pitt.edu/ojs/index.php/Iberoamericana/article/download/3169/3351 Consulta: 14 de diciembre de 2012.

\section{(c) (i) (9)}

Este obra está bajo una licencia de Creative Commons Reconocimiento-NoComercial-SinObraDerivada 4.0 Internacional. 